\title{
Enamel Factors Regulate Expression of Genes Associated With Cementoblasts
}

Y. Tokiyasu, ${ }^{\dagger}$ T. Takata, ${ }^{\ddagger}$ E. Saygin, ${ }^{\S}$ and $M$. Somerman ${ }^{*}$

Background: In order to design predictable periodontal regenerative therapies, it is important to understand the responsiveness of cells within the local environment to factors considered attractive candidates. The aim of this study was to determine the effect of an enamel matrix derivative (EMD) on cementoblast behavior in vitro and in vivo.

Methods: Osteocalcin (OC) promoter SV40 transgenic mice were used to obtain cementoblasts. For comparison, preosteoblasts from these mice, as well as another murine preosteoblast cell line, MC3T3-E1 cells, were used. Cells exposed to EMD were evaluated for changes in: 1) proliferation over an 8-day period by cell counting; 2) gene expression using Northern blot analysis; and 3) biomineralization by von Kossa stain, in vitro and by preparing histological samples from implants retrieved from immunodeficient (SCID) mice, where cementoblasts were treated with EMD prior to implantation.

Results: EMD promoted proliferation of all cell types. EMD down-regulated osteocalcin transcripts in cementoblasts and MC3T3-E1 cells and up-regulated osteopontin gene expression markedly in MC3T3-E1 cells and slightly in cementoblasts at day 8. In vitro, EMD decreased cementoblast-mediated biomineralization. In contrast, mineralization was noted in implants retrieved from SCID mice, where cells were pretreated with EMD.

Conclusion: These results indicate that EMD can influence activities of cementoblasts and osteoblasts, and thus may be able to regulate cell activities at a periodontal regenerative site. J Periodontol 2000;71:1829-1839.

\section{KEY WORDS}

Protein, enamel matrix; osteoblasts; dental cementum; osteoclasts; osteopontin; sialoglycoprotein.

\footnotetext{
* Department of Periodontics/Prevention/Geriatrics, University of Michigan, School of Dentistry, Ann Arbor, MI.

$\dagger$ Department of Pediatric Dentistry, Mekai University, Sakado, Saitama, Japan.

‡ Department of Oral Pathology, Hiroshima University, School of Dentistry, Hiroshima, Japan.

$\S$ Department of Chemistry, University of Missouri, Rolla, MO.

|| Department of Pharmacology, University of Michigan, School of Medicine.
}

$\mathrm{P}$ eriodontal diseases are marked by destruction of periodontal support; i.e., periodontal ligament (PDL), cementum, and bone, with subsequent tooth loss if left untreated. The recognition that periodontal regeneration can be achieved (formation of new bone, new cementum, and supportive PDL) has resulted in attempts to understand the cellular and molecular mechanisms and factors regulating formation of these tissues during development and regeneration. ${ }^{1}$ This enhanced knowledge also has resulted in increased efforts at the clinical level to develop improved regenerative therapies based on sound biological principles. $^{2}$

As one approach to understanding the mechanisms and factors involved in regenerating periodontal tissues, researchers have mapped the temporal and spatial expression of specific factors during development of these tissues. While the mechanisms, cells, and factors involved in regenerating periodontal tissues do not exactly follow those associated with development, investigations focused at developmental stages have provided important information as to potential factors that may prove beneficial during regeneration of periodontal tissues. In this regard, one area that has received attention, the use of enamel factors to promote periodontal regeneration, is based on the knowledge that epithelialmesenchymal interactions are required for formation of several tissues. For example, appropriate interactions be- 
tween neural crest cells and epithelial cells result in formation of enamel and dentin. ${ }^{3,4}$ It is less clear whether epithelial-mesenchymal signaling molecules are involved in cementum formation and in development of a functional periodontal ligament. Several molecules associated with the epithelial root sheath have been suggested to have a role in controlling root development and these include laminin, ${ }^{5}$ amelin (ameloblastin, sheathlin), ${ }^{6-8}$ and other enamel and enamel-like products. ${ }^{9-12}$

Importantly, while it is not established whether epithelial-mesenchymal interactions are required for cementum formation, enamel-like molecules such as a porcine enamel matrix derivative (EMD) have been reported to promote proliferation, migration, adhesion, and differentiation of cells associated with healing periodontal tissues in vivo. ${ }^{13}$ With regard to cell differentiation, this would be analogous to the known ability of ameloblasts-odontoblasts to secrete factors required for the development of dentin and enamel; i.e., epithelial-mesenchymal interactions.

Data from several studies suggest that EMD, where the principal protein is amelogenin, can augment cell activities both in vitro and in vivo. Hammarstrom and colleagues, using monkey models, reported enhanced regeneration of periodontal tissues; i.e., bone, cementum, and PDL with the use EMD versus vehicle. ${ }^{14,15}$ Further studies in humans have reported promising results as measured histologically and also based on clinical attachment levels and subtraction radiography. ${ }^{16,17}$ In vitro studies indicate that PDL cells exposed to EMD exhibit enhanced protein production, cell proliferation, and ability to promote mineral nodule formation. ${ }^{18}$

These findings suggest strongly that EMD has a positive effect on cells within a healing periodontal site; however, the mechanism by which EMD promotes cell activity, as well as the selectivity of EMD for specific cell types, remains unknown. As a next step to address these issues, we determined whether EMD had an effect on gene expression, cell proliferation, and mineral nodule formation in cementoblasts and also preosteoblasts in vitro. Since previous studies, based on temporal and spatial localization of enamel-like proteins during root development, suggested that they promote cementoblast activity, it was important to determine whether EMD had a direct effect on cementoblast behavior. In addition, OCT-1 cells, an immortalized preosteoblast calvaria cell line from OC-TAg transgenic mice and a murine osteoprogenitor cell line, MC3T3-E1 cells, were used.

As presented below, the results indicated that EMD enhances proliferation of all cells types studied and also alters gene expression, but in different fashions for each cell type. Further, EMD modifies mineral nodule formation both in vitro and in vivo.

\section{MATERIALS AND METHODS}

\section{Cell Culture}

Methods used to generate immortalized cementoblasts have been previously described in detail. ${ }^{19}$ Briefly, osteocalcin promoter-driven SV-40 TAg transgenic mice (OC-TAg) (provided by Dr. Jolene Windle) were used to obtain cementoblasts exclusive from the surrounding periodontal liagment (PDL) fibroblasts. ${ }^{20}$ These cells are termed osteocalcin promoter cementoblasts (OC-CM cells). The rationale here is that only those cells expressing osteocalcin, root surface cells/cementoblasts, and not PDL fibroblasts, would be immortalized and therefore survive in vitro. In previous studies we demonstrated that in situ osteocalcin is expressed by root surface cells, but not by cells within the periodontium. ${ }^{21}$ Mice at day 41 of development (day 0, vaginal plug date) were used to obtain cells. Selection of this time point was based on previous studies, ${ }^{21}$ where we showed that at day 41 of development in mice, root cementum formation is well established and cells along the root surface, cementoblasts, but not PDL cells express transcripts for bone sialoprotein (BSP) and osteocalcin (OCN), markers associated with cells involved in promoting mineralized tissues. This genotype is maintained when cells are cultured. All procedures involving mice were performed in compliance with regulations administered by the University of Michigan Unit for Lab Animal Medicine.

To obtain root surface cells, mandibular first molars were removed using a dissecting microscope to separate PDL from surrounding alveolar bone and cells released using collagenase/trypsin cocktail. ${ }^{19,21,22}$ Cells were maintained in Dulbecco's modified Eagle's medium (DMEM)," supplemented with $10 \%$ fetal bovine serum (FBS) containing $100 \mathrm{U} / \mathrm{ml}$ of penicillin\# and $100 \mu \mathrm{g} / \mathrm{ml}$ of streptomycin ${ }^{\#}$ in a humidified atmosphere of $5 \% \mathrm{CO}_{2}$ at $37^{\circ} \mathrm{C}$. A clonal cell line, OC-CM30 established from the parent OC-CM cell line, was used. This cell population exhibits strong transcripts for both BSP and OCN. Two murine osteoblast cells lines also were used for these studies as comparisons.

OCT-1 cells, (a gift from Dr. D. Chen) are a preosteoblast cell line generated from calvaria of OC-TAg mice. ${ }^{20}$ These cells were selected to control for possible variations in response of cells obtained from OCTAg mice regardless of the tissue from which the cells were generated. These cells require BMP 2 in order to differentiate along the osteoblast pathway. For studies here, cells were maintained in culture using the same media as for OC-CM cells and BMP was not included. The other cell line selected, MC3T3-E1, is osteoprogenitor cells derived from new born calvaria that are known to differentiate along the osteoblast pathway in

Il Emdogain, Biora AB, Malmo, Sweden \# Gibco, BRL, Gaithersburg, MD. 
the presence of ascorbic acid. ${ }^{23}$ These cells were selected since they provide an excellent model for determining the ability of factors to regulate osteoblast differentiation. ${ }^{23-25}$ Upon exposure to ascorbic acid they express mRNA for OCN and BSP, both markers of active osteoblasts. These cells were maintained in $\alpha$-modified Eagle's Medium ${ }^{\#}$ supplemented with $10 \%$ FBS and antibiotics as above and used between passages 10 to 15 .

\section{Cell Proliferation}

For proliferation assays, cells were plated in 24-well dishes, at 5,000 cells/ml in triplicate wells and cultured in media described above, in the presence of ascorbic acid. After allowing cells to adhere overnight, media were changed to $2 \%$ FBS containing EMD ( 5 to $100 \mu / \mathrm{ml}$ ) with media changed on days 2 and 5 .

Cells were harvested on days 2, 5, and 7 and cell number determined by Coulter counter. Appropriate controls included cells cultured in media without EMD, containing $10 \%$ FBS, a positive control, or $2 \%$ FBS, a negative control, where in initial studies we showed that cells can survive over a 10 -day period in $2 \% \mathrm{FBS}$, but exhibit minimal cell growth. Experiments were performed on 3 separate occasions.

\section{Northern Blot Analysis}

For analysis of gene expression, cells were plated in $100 \mathrm{~mm}$ dishes at an initial density of 50,000 cells per dish. After a 24-hour attachment period, media were changed to media with or without ascorbic acid, with or without $100 \mu \mathrm{g} / \mathrm{ml} \mathrm{EMD,} \mathrm{and} \mathrm{with} \mathrm{5 \%} \mathrm{FBS} \mathrm{for} \mathrm{OC-}$ CM and OCT- 1 cells and 2\% FBS for MC3T3-E1 cells. The reason for using 5\% FBS for OC-CM cells was to parallel the mineralization assays. Early on in these studies we noted that OC-CM cells cultured in $2 \%$ FBS expressed low levels of BSP and exhibited limited ability to promote mineral nodule formation. Thus for consistency, while comparable results on gene expression were noted with $2 \%$ FBS, results using $5 \%$ FBS are shown. RNA was isolated at days 3, 5, and 8 for OCCM cells, at days 3 and 8 for OCT- 1 cells and day 8 for MC3T3-E1 cells, using the procedure of Xie and Rothblum. ${ }^{26}$ Briefly, for Northern blot analyses, total RNA was isolated using a guanidinium isothiocynate procedure and quantified by spectrophotometer. Total RNA (10 to $20 \mu \mathrm{g}$ ) was denatured, fractionated, on a $6 \%$ formaldehyde, $1.2 \%$ agarose gel, transferred to a nylon membrane** and cross-linked by UV irradiation. ${ }^{\dagger \dagger}$

Blots were hybridized with random-primed ${ }^{32} \mathrm{P}$ radiolabeled probes ${ }^{\ddagger \ddagger}$ and were exposed to film at $-70^{\circ} \mathrm{C}$ with intensifying screens for 24 to 72 hours.

Probes used for Northern blots were BSP $=$ M-BSP consists of $1 \mathrm{~kb}$ of mouse cDNA in PCR II ${ }^{27}$ (a gift from Drs. M. Young and L. Fisher, NIDCR/NIH, Bethesda, Maryland); OPN = MCP-3 consists of $1 \mathrm{~kb}$ of mouse OPN cDNA in CR II ${ }^{28}$ (a gift from Drs. M. Young and L. Fisher); OCN $=400 \mathrm{bp}$ of mouse OCN cDNA originally cloned into pSP65 cloning vector was transferred to Bluescript $\mathrm{Sk}^{29}$ (obtained from Dr. J. Wozney, Genetic Institute, Cambridge, Massachusetts). Ethidium bromide stained gels, 18S, were used to determine relative RNA loading. To normalize for differences in loading, data were quantitated by obtaining relative density of specific RNAs and 18S RNA and expressing data as a ratio of specific RNA to 18S RNA. Experiments were performed at least 2 times.

\section{Mineralization Assay}

In vitro. The in vitro mineralization assay was performed on cementoblasts and OCT-1 cells as reported previously. ${ }^{19,25,30}$ Cells were plated at $1.0 \times 10^{4}$ cells $/ \mathrm{cm}^{2}$ in 24-well plates. Upon confluence, designated day 0 , media were removed and cells were incubated in DMEM containing 5\% FBS and supplemented with $50 \mu \mathrm{g} / \mathrm{ml}$ ascorbic acid and $10 \mathrm{mM} \beta$-glycerol phosphate, \pm EMD $(5,50$, or $100 \mu \mathrm{g} / \mathrm{ml})$. Samples were processed on day 8 and von Kossa assay performed to detect mineral nodule formation. Experiments were performed 3 times.

Ex vivo. The procedures described below were approved by the University of Michigan Committee and the Unit for Laboratory Animal Medicine (ULAM), and were compliant with State and Federal laws as well as the guiding principles of use and care of animals. To avoid host rejection of cell transplants, immunocompromised mice (SCID mice) $\S \S$ were employed to serve as subcutaneous transplant recipients. Previous studies have shown that this animal model provides an excellent environment for supporting formation of mineralized tissues by several implanted cell types, including human bone marrow stromal cells, ${ }^{31}$ mouse osteoblastic cells (MC3T3-E1 cells), ${ }^{32}$ and human cementum-derived cells. ${ }^{33}$ Transplant vehicles were prepared by soaking $3 \times 3 \mathrm{~mm}$ squares of a mixture of hydroxyapatite and collagen ${ }^{\|\|}$ in DMEM containing 10\% FBS for 30 to 45 minutes, followed by compression between filter paper to remove air. Cells treated for 24 or 72 hours with 50 $\mu \mathrm{g} / \mathrm{ml}$ of EMD in vitro were trypsinized, pelleted, and resuspended to approximately $2.0 \times 10^{6}$ cells/per ml. The sponges alone served as negative controls and untreated cells served as positive controls. The compressed sponges were allowed to absorb the cell suspension by capillary action and held at $37^{\circ} \mathrm{C}$ until implantation. SCID mice were anesthetized using

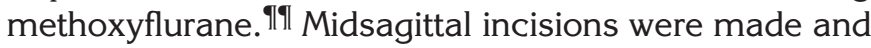

\footnotetext{
** Darakib-UV, Stratagene, Inc., La Jolla, CA

$\dagger \dagger$ Stratalinker, Stratagene, Inc.

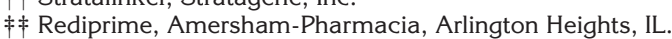

$\S \S$ C.B-17 SCID, Taconic, Germantown, NY.

|| Zimmer Corp., Warsaw, IN.

II Mallincrodt Veterinary, Mundelein, IL.
} 


\section{CEMENTOBLASTS (OC-CM)}

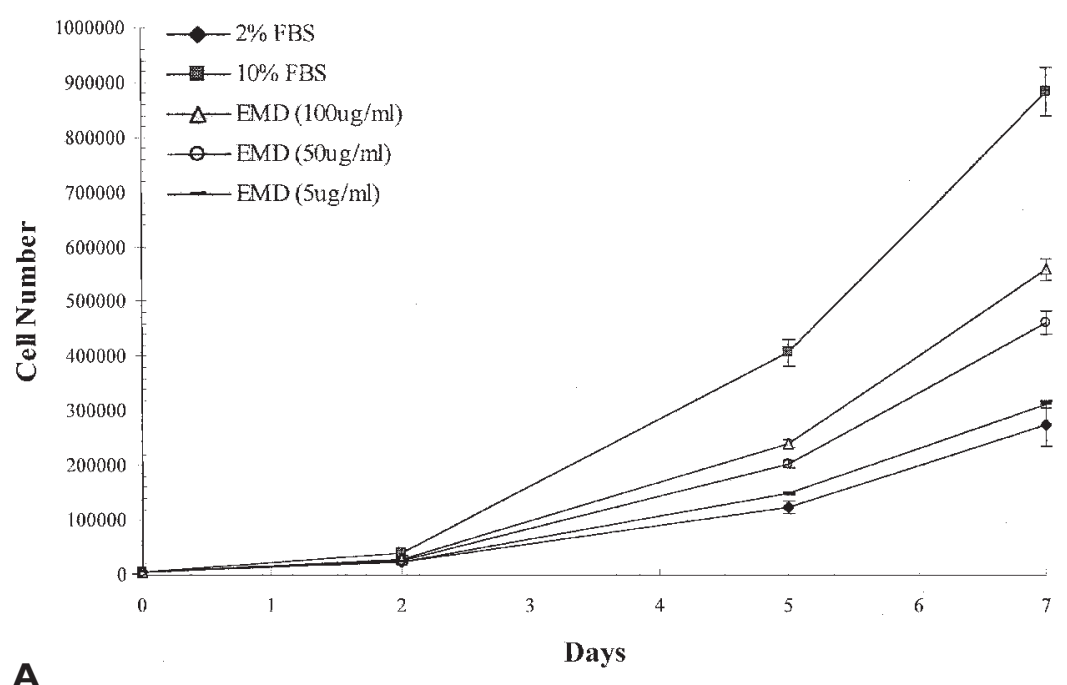

A

OCT-1

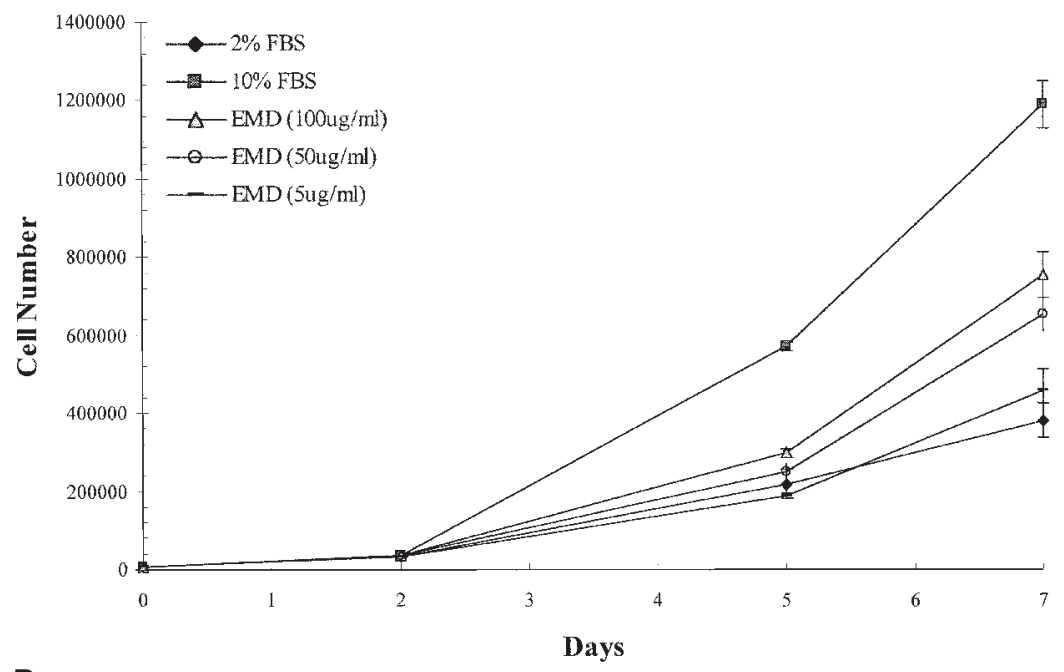

B

\section{MC3T3-E1}

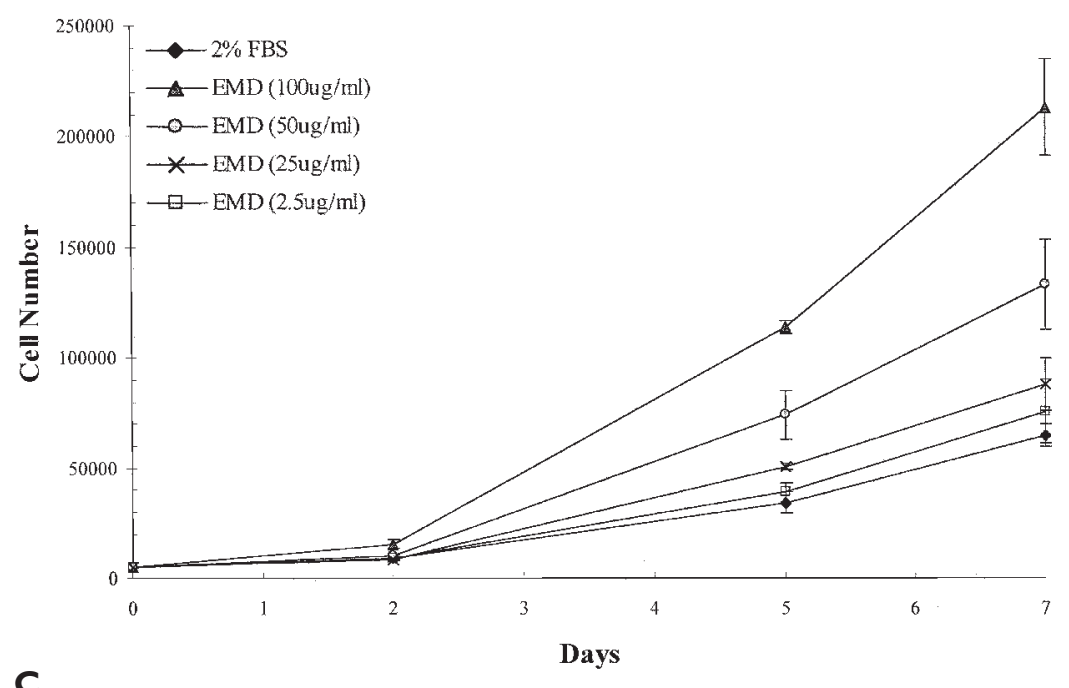

implants inserted into the surgical pockets (4 in 2 animals with 2 on each side) and the sites stapled closed. Eight SCID mice were used. Implants were removed 6 weeks following surgery, fixed using 10\% neutral buffered formalin, and embedded in parraffin. Five-micron sections were prepared and stained with hematoxylin and eosin.

\section{Statistical Analysis}

For statistical analysis, one way analysis or variance (ANOVA) and Tukey Kramer multiple comparison tests were performed.

\section{RESULTS}

\section{Cell Proliferation}

As shown in Figure 1 and Table 1, EMD promoted proliferation of all cell types assayed. A dose-response effect was noted, where by day 5 , cells treated with 50 or $100 \mu \mathrm{g} / \mathrm{ml} \mathrm{EMD}$ exhibited enhanced cell proliferation when compared to $2 \%$ FBS control.

\section{Northern Blot Analysis}

Results for cells treated with EMD are summarized in Table 2, where data are expressed as a ratio of specific RNA to 18S RNA and detailed below, with Northern blots presented in Figures 2 and 3.

\section{OC-CM Cells}

Day 3 (Fig. 2A). Cells exposed to ascorbic acid in the absence of EMD had greater levels of OPN mRNA when compared with nonascorbic acid treated cells. At day 3, cementoblasts exposed to EMD, -AA, showed a slight increased expression for OPN mRNA when compared to 5\% FBS control. In the presence of AA this effect was not apparent and in fact a slight decrease in OPN mRNA was noted. BSP and OCN mRNAs were not detected at this time.

Day 5 (Fig. 2B). At day 5, BSP and OCN mRNA expression was apparent in control cells, where AA enhanced expression when compared with cells not exposed to AA. Cells exposed to EMD in the absence of AA exhibited a marked

Figure I.

Effect of EMD on cell proliferation. A. OC-CM 30: cementoblasts from OC-TAg mice. B. OCT-I: preosteoblasts from OC-TAg mice. C. MC3T3-E I: preosteoblasts from mouse calvaria. Cells were cultured in media with $2 \%$ FBS, $50 \mu \mathrm{g} / \mathrm{ml}$ ascorbic acid, \pm EMD. For OCT-I and OC-CM cells, a $10 \%$ FBS control was used. Cell number was determined by Coulter counter on days 2, 5, and 7. Statistical analysis is shown in Table 1. 
Table I.

Statistical Analysis for Figure 1

\begin{tabular}{|c|c|c|c|c|c|c|c|c|}
\hline \multirow[b]{2}{*}{ Cementoblasts (OC-CM) } & \multicolumn{4}{|c|}{ Day 5 (2\% FBS + EMD) } & \multicolumn{4}{|c|}{ Day 7 (2\% FBS + EMD) } \\
\hline & 5 ug & \multicolumn{2}{|c|}{50 ug } & 100 ug & 5 ug & \multicolumn{2}{|c|}{50 ug } & 100 ug \\
\hline $2 \%$ FBS & \multirow[t]{3}{*}{ n.s. } & \multicolumn{2}{|c|}{$\ddagger$} & $\neq$ & \multirow[t]{3}{*}{ n.s. } & \multicolumn{2}{|c|}{ t } & $\ddagger$ \\
\hline +EMD (5ug) & & \multicolumn{2}{|c|}{ * } & $\ddagger$ & & \multicolumn{2}{|c|}{ * } & $\ddagger$ \\
\hline +EMD (50ug) & & & & n.s. & & & & n.s. \\
\hline \multirow[t]{2}{*}{ Preosteoblasts (OCT-I) } & \multicolumn{4}{|c|}{ Day 5 (2\% FBS + EMD) } & \multicolumn{4}{|c|}{ Day 5 (2\% FBS + EMD) } \\
\hline & 5 ug & \multicolumn{2}{|c|}{50 ug } & 100 ug & 5 ug & \multicolumn{2}{|c|}{50 ug } & 100 ug \\
\hline $2 \%$ FBS & \multirow[t]{3}{*}{ n.s. } & \multicolumn{2}{|c|}{ n.s. } & $\ddagger$ & n.s. & \multicolumn{2}{|c|}{$\ddagger$} & $\ddagger$ \\
\hline +EMD (5ug) & & \multicolumn{2}{|c|}{ * } & $\ddagger$ & & \multicolumn{2}{|c|}{$\ddagger$} & $\ddagger$ \\
\hline +EMD (50ug) & & & & n.s. & & & & n.s. \\
\hline \multirow[t]{2}{*}{ Preosteoblasts (MC3T3-EI) } & \multicolumn{4}{|c|}{ Day 5 (2\% FBS + EMD) } & \multicolumn{4}{|c|}{ Day 7 (2\% FBS + EMD) } \\
\hline & $2.5 \mathrm{ug}$ & 25 ug & 50 ug & 100 ug & $2.5 \mathrm{ug}$ & 25 ug & $50 \mathrm{ug}$ & 100 ug \\
\hline $2 \%$ FBS & n.s. & * & $\ddagger$ & $\ddagger$ & n.s. & n.s. & t & $\ddagger$ \\
\hline +EMD (2.5ug) & & n.s. & $\ddagger$ & $\ddagger$ & & n.s. & $\dagger$ & $\ddagger$ \\
\hline +EMD (25ug) & & & $\dagger$ & $\ddagger$ & & & * & $\ddagger$ \\
\hline +EMD (50ug) & & & & $\ddagger$ & & & & $\ddagger$ \\
\hline
\end{tabular}

n.s. = not significant; * $P<0.05 ; \dagger P<0.01 ; \neq P<0.001$.

Table 2.

\section{Effect of EMD on Gene Expression*}

\begin{tabular}{|c|c|c|c|c|c|c|c|c|c|c|}
\hline \multirow[b]{3}{*}{ mRNA } & \multicolumn{6}{|c|}{$\mathrm{OC}-\mathrm{CM}$} & \multirow{2}{*}{\multicolumn{2}{|c|}{$\frac{\text { OCT-I }}{\text { Day } 8}$}} & \multirow{2}{*}{\multicolumn{2}{|c|}{$\frac{\text { MC3T3-EI }}{\text { Day } 8}$}} \\
\hline & \multicolumn{2}{|c|}{ Day 3} & \multicolumn{2}{|c|}{ Day 5} & \multicolumn{2}{|c|}{ Day 8} & & & & \\
\hline & -A.A. & +A.A. & -A.A. & + A.A. & -A.A. & + A.A. & -A.A. & +A.A. & -A.A. & $+\mathrm{A} \cdot \mathrm{A}$ \\
\hline \multicolumn{11}{|l|}{ OPN } \\
\hline -EMD & 1.7 & 2.7 & 0.9 & 2.5 & 0.3 & 0.8 & 3.0 & 5.0 & 0.3 & 0.8 \\
\hline$+\mathrm{EMD}$ & 2.3 & 1.8 & 1.7 & 2.3 & 1.7 & 2.2 & 2.8 & 4.4 & 2.0 & 2.0 \\
\hline \multicolumn{11}{|l|}{ BSP } \\
\hline -EMD & N.E. ${ }^{\dagger}$ & & 1.0 & 2.5 & 2.5 & 1.8 & N.E. & & 0.9 & 2.5 \\
\hline+ EMD & & & 1.0 & 1.7 & 1.8 & 2.4 & & & 1.5 & 2.0 \\
\hline \multicolumn{11}{|l|}{ OCN } \\
\hline -EMD & N.E. & & 0.6 & 2.8 & 1.5 & 1.8 & N.E. & & 0.0 & 1.5 \\
\hline+ EMD & & & 0.0 & 0.7 & 0.3 & 1.8 & & & 0.0 & 0.0 \\
\hline
\end{tabular}

* Summary of Northern blot analysis shown in Figures 2 and 3. Data expressed as specific RNA/18S RNA ratio. Representative results from one experiment are shown, where experiments were repeated twice for OCT-1 cells and three times for MC3T3-E1 and OC-CM cells with comparable results.

$\dagger$ Not expressed. 


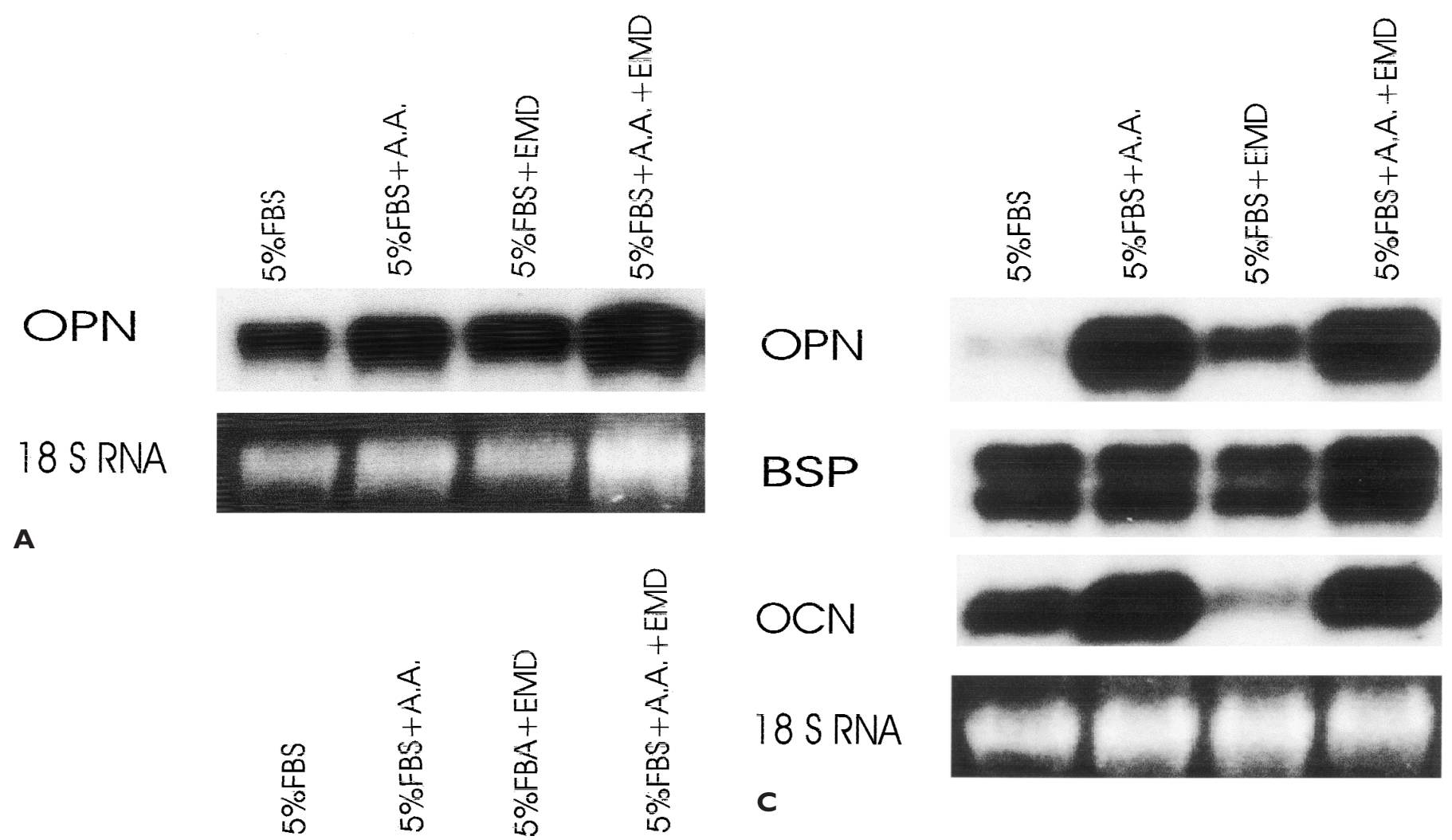

OPN

\section{BSP}

OCN

\section{S RNA}

B

down regulation of OCN mRNA when compared with 5\% FBS control. Further, while OCN transcripts were noted in cells treated with $\mathrm{EMD},+\mathrm{AA}$, expression remained lower when compared to 5\% FBS, AA control. An increased expression of OPN mRNA was apparent in cells treated with $\mathrm{EMD}$ in the absence of $\mathrm{AA}$, when compared to $5 \%$ FBS control, similar to that observed at day 3 .

Day 8 (Fig. 2C). At day 8 , the ability of EMD to enhance OPN expression and inhibit OCN expression persisted for cells exposed to EMD, without AA. In addition, a modest increase in BSP mRNA level was noted in cells exposed to EMD in the presence of AA when compared with 5\% FBS, AA control and this response was reproducible.

\section{OCT-1 Cells (Fig. 3A)}

At all time points, cells with or without $\mathrm{AA}$ and/or EMD did not express transcripts for BSP or OCN (data not shown). At day 8 no significant differences were noted in OPN transcripts between EMD treated versus untreated cells.

\section{MC3T3-E1 Cells (Fig. 3B)}

Northern blot analysis was done at day 8 only. As seen in Figure 3B, EMD blocked AA mediated induction of OCN 


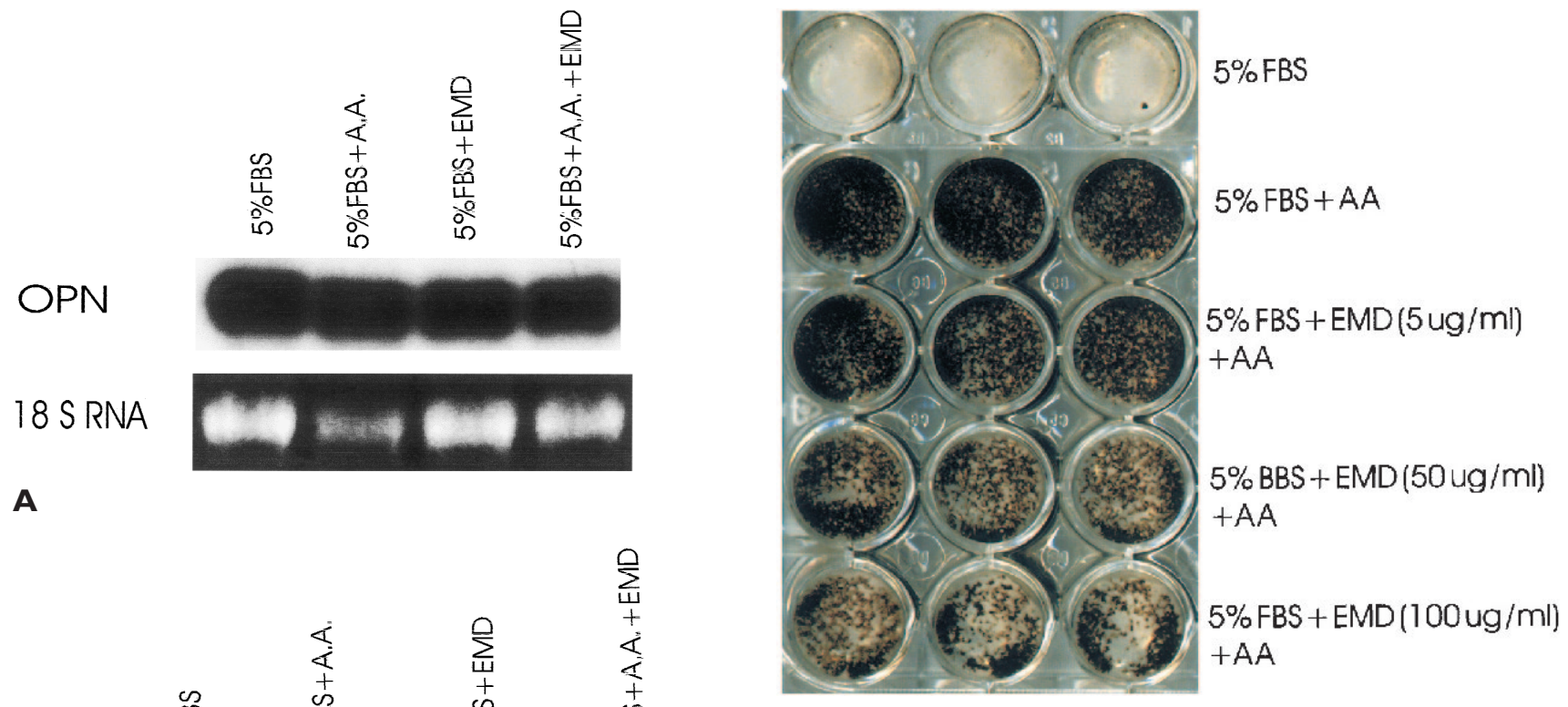

Figure 4.

In vitro mineralization. Effect of pretreatment of cementoblasts with EMD on biomineralization in vitro. For these studies, cells were cultured in media containing 5\% FBS, $50 \mu \mathrm{g} / \mathrm{ml} \mathrm{AA}, 10 \mathrm{mM}$ B-glycerophosphate and EMD at 5, 50, or $100 \mu \mathrm{g} / \mathrm{ml}$. On day 8, von Kossa stain was used to determine extent of mineral nodule formation. EMD inhibited OCCM mediated mineral nodule formation, in a dose-dependent fashion, where at $5 \mu \mathrm{g} / \mathrm{ml}$ EMD had no inhibitory effect, but $50 \mu \mathrm{g} / \mathrm{ml}$ EMD and $100 \mu \mathrm{g} / \mathrm{ml}$ EMD had an inhibitory effect on mineral formation.

EMD inhibited OC-CM mediated mineralization in vitro in a dose-response fashion. At $5 \mu \mathrm{g} / \mathrm{ml}$ of EMD mineral nodule formation was comparable to control cells treated with AA plus $\beta$-glycerophosphate, however, at $50 \mu \mathrm{g} / \mathrm{ml}$ and at $100 \mu \mathrm{g} / \mathrm{ml}$ mineral nodule formation was decreased but not blocked. OCT-1 cells did not promote mineral formation under any of the conditions examined (data not shown).

In vivo (Fig. 5). When OC-CM cells were first treated with EMD and then transplanted into SCID mice, they were able to promote mineral nodule formation (Fig. $5 \mathrm{C}$ and $\mathrm{D})$. Interestingly, when compared with sections obtained from cells treated with $2 \%$ or $10 \%$ serum without EMD prior to transplantation (Fig. 5B), approximately $50 \%$ of the sections, obtained from cells treated with EMD for 24 or 72 hours prior to transplantation, exhibited areas with a greater cell number to mineral tissue ratio (Fig. 5D). The pattern of cell-mineral formation shown in Figure 5D was never observed in sections obtained from cells treated with $2 \%$ or $10 \%$ FBS.

\section{DISCUSSION}

The results presented here indicate that EMD has the ability to promote a variety of activities in mesenchymal derived cells. Specifically, these studies focused on the interaction of cementoblasts with EMD, but 2 osteoblast cell lines also were examined as a com- 


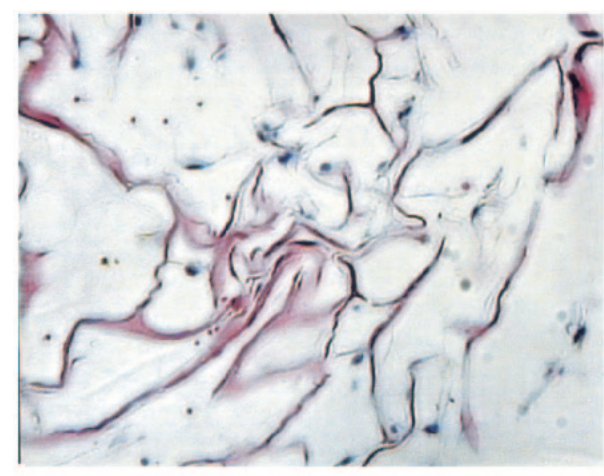

A. Negative control

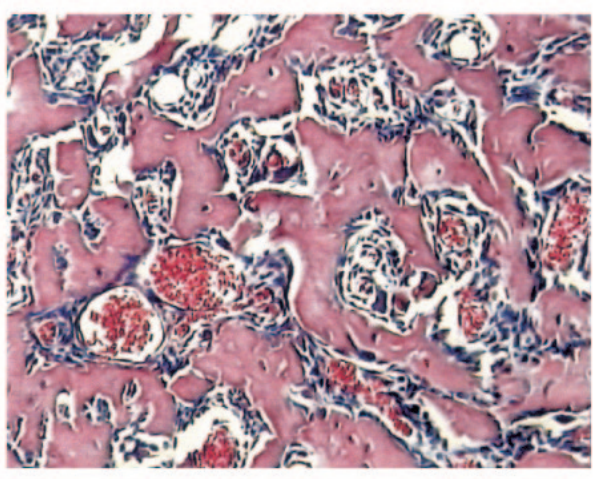

C. EMD

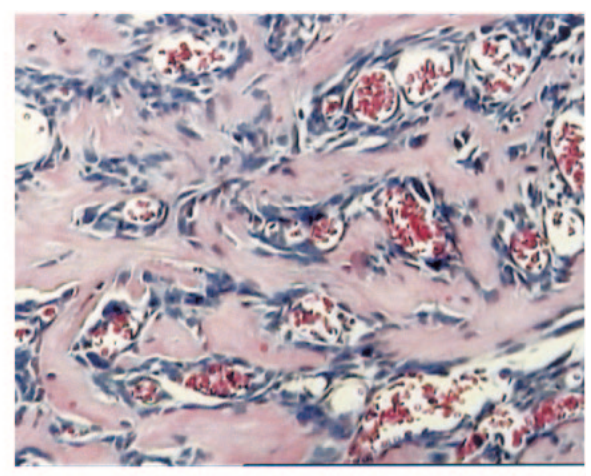

B. Positive control

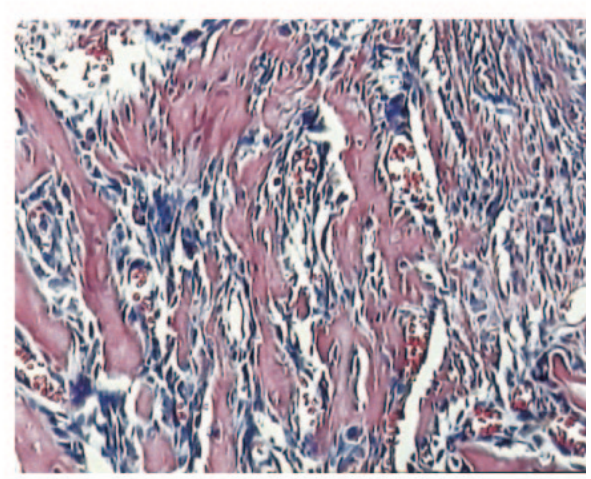

D. EMD

Figure 5.

In vivo mineralization. Effect of pretreatment of cementoblasts with EMD on biomineralization, in vivo. For these studies cells were pretreated with $50 \mu \mathrm{g} / \mathrm{ml}$ EMD for 24 or 72 hours and then seeded on sponges and transplanted subcutaneously in SCID mice. Grafts were retrieved 6 weeks later, fixed and $5 \mu$ sections, prepared, and H\&E stained. A. Graft only control. B. OC-CM cells, in 10\% FBS. Note mineral formation C. OC-CM cells pretreated with EMD for 24 hours prior to transplantation. Note mineral formation. D. OC-CM cells pretreated with EMD for 24 hours prior to transplantation. Note mineral formation; however, when compared with B or C, an increase in cell to mineral ratio was noted. This finding was observed in approximately $50 \%$ of the tissues obtained from cells pretreated with EMD for 24 hours (shown here), as well as 72 hours (data not shown), but not in cells pretreated with 10\% FBS (Fig. 5B) or 2\% FBS (data not shown).

but the possibility that amelogenin itself or other as yet to be identified molecules present in EMD work through growth factor associated receptors such as receptor tyrosine kinases and serine-threonine receptor kinases needs to be explored. 34,35 Regardless of the mechanism, factors that promote proliferation of cells within a wound healing would be advantageous for providing a critical mass of cells required for synthesizing the necessary regenerative matrix.

Beyond the effect of EMD on cell proliferation, evidence from the in vitro models suggest that EMD may alter gene expression when used for regenerative therapies. The most dramatic effect of EMD was on OCN gene expression. EMD decreased OCN expression in both the cementoblast cell line and the preosteoblast cell line, MC3T3-E1 cells. The ability of an agent that promotes proliferation to decrease expression of genes associated with differentiation is not surprising. For example, evidence from several in vitro studies indicate that the strong mitogen, PDGF, promotes osteoblast proliferation, but decreases expression of osteoblast-associated genes, in vitro. ${ }^{36-39}$

Cementoblasts exposed to EMD, +AA for 8 days, exhibited a modest increase in BSP gene expression when compared with 5\% FBS, +AA control. In contrast, EMD did not alter BSP

parison to cementoblasts. Importantly, and as reported previously for human PDL cells, ${ }^{18}$ EMD promoted proliferation of all 3 cell lines. In addition, EMD altered gene expression of all cell types, but the pattern of change was different for each cell type. EMD inhibited cementoblast-mediated mineral nodule formation in vitro, while mineral formation was observed in transplants obtained from SCID mice, when cells were pretreated with EMD in vitro prior to transplantation.

Based on these findings, as well as past studies, it is clear that EMD promotes cell proliferation, and thus has properties similar to growth factors such as platelet-derived growth factor (PDGF). Previously, we explored the possibility that EMD may contain growth factors known to mediate proliferation of PDL cells; e.g., PDGF and IGF and others, and based on the immunoassays used, these molecules were not identified in EMD. ${ }^{18}$ At this point, we do not know the mechanism by which EMD promotes cell proliferation, transcripts in 8-day cultured MC3T3-E1 cells. The reason for this disimilarity in response to EMD is most likely related to differences in stage of cell maturation versus differences in response of osteoblasts versus cementoblasts to EMD. We also determined the effect of EMD on OPN gene expression, where OPN gene and product are found in high concentrations in bones and teeth. ${ }^{40}$ By day 8 , both MC3T3-E1 cells and cementoblasts, when exposed to EMD, exhibited an increase in OPN mRNA levels.

While these are in vitro results, these data suggest that EMD can alter genes associated with cementoblast and osteoblast maturation. In examining the genes that were decreased by EMD, it is interesting to note that the most dramatic effect was on OCN mRNA levels. Osteocalcin, based on time of expression, appears to play a role in early phases of mineralization, but in addition, may also regulate extent of crystal growth. ${ }^{41-43}$ Similarly, OPN also appears to regulate extent of crystal growth and 
in addition promotes migration and attachment of both osteoblasts and osteoclasts to sites of bone remodeling. ${ }^{40,44,45}$ However, unlike EMD's inhibitory effect on OCN transcripts, EMD promoted expression of OPN mRNA, in vitro. Thus, the ability to regulate crystal growth, and hence overgrowth of mineralized tissues, may be a function of EMD. This function may be coupled with EMD's ability to maintain or slightly enhance BSP transcripts. BSP is a mineral-associated protein that promotes attachment of both osteoblasts and osteoclasts and, in cell-free systems, acts as a nucleator of hydroxyapatite crystal formation. ${ }^{41,46}$

Conceivably, EMD could act by first promoting cell proliferation, thereby providing a sufficient cell population to synthesize the appropriate extracellular matrix. Having the critical cell mass, EMD may then act by regulating the level of mineralization versus soft connective tissue formation (i.e., PDL formation).

To determine the effects of EMD on cementoblastmediated mineralization, in vitro and in vivo assays were used. In the in vitro model, EMD inhibited cementoblast-mediated mineral nodule formation in a doseresponse fashion. This is in contrast to previous studies by Gestrelius et al., ${ }^{18}$ where EMD was shown to promote PDL-mediated mineral formation. There are several possibilities for these discrepancies, including differences in cell types and experimental design between these studies. In the studies here, cementoblasts were cultured in the presence of AA, $\beta$-glycerophosphate $\pm E M D$. In contrast, in the previous studies with PDL cells dexamethasone was included in the medium. Further, cementoblasts promote mineral nodule formation within 8 days, while for PDL cells, 21 days is required. Therefore, in vitro it is not surprising that such differences in EMD's effects on mineralization were noted. While EMD decreased OC-CM mediated-mineral formation in vitro, when cells were first treated with EMD and then implanted subcutaneously in SCID mice, cells pretreated with EMD retained the ability to promote mineral formation. Conceivably, EMD in vivo may provide the environment necessary to promote regeneration by enhancing cell proliferation. While more studies are needed to confirm this, increased cellularity noted in some sections obtained from implants where cells were pretreated with EMD versus sera treated control cells (Fig. 5B versus 4D), supports this concept.

With regard to the reported effects of EMD on mineralization, it is interesting to review the effects of amelogenin on hydroxyapatite formation, where there exists evidence that both amelogenin and enamelin play a role in initiation of mineralization, ${ }^{47-51}$ while others indicate that amelogenin has no specific crystal-modulating properties. ${ }^{52}$ Possible explanations for differences noted include assay systems and purity, species and nature of the amelogenin used; i.e., in the first 2 cases bovine and porcine amelogenins were used, while in the latter situation a recombinant mouse amelogenin was used. ${ }^{51-53}$ Furthermore, amelogenin is processed rapidly during amelogenesis, where studies in pigs have shown that ameloblasts secrete a 25KDa nascent protein into the newly formed enamel which is processed into smaller fragments (23K, 20K, 13K) during maturation. ${ }^{54}$ The exact role of these individual fragments remains unknown, but may explain, in part, differences in activities of amelogenin reported by different laboratories. The EMD used for the studies here is of porcine origin. However, whether amelogenin was the factor responsible for inhibition of mineralization needs further investigation.

Based on the results summarized here and on data from clinical studies using EMD, it is clear that EMD can have a positive effect on periodontal tissues. However, clinical results are often not predictable. While it is possible to imagine that EMD would be well suited for slow-delivery therapy where first phase release would bring the critical mass of cells to the healing site and, in the second phase, EMD and/or other factors in combination would act to regulate expression of genes and their products. Continued studies targeted at defining the factor(s) in EMD responsible for promoting cell proliferation and altering gene expression; determining the signaling pathways triggered by EMD; determining whether EMD influences expression of metaloproteinases; and designing appropriate delivery systems for EMD, as well as other factors, will enable us to design more predictable clinical therapies based on sound biological principles.

\section{ACKNOWLEDGMENTS}

This study was supported by Biora, Inc., Chicago, Illinois and NIH/NICDR grant DE09532. The authors wish to thank Bev Sutton for assistance in preparing this manuscript and the Center for Biorestoration of Oral Tissues for support of core programs.

\section{REFERENCES}

1. Wikesjö UM, Selvig KA, eds. Periodontal wound healing and regeneration. Periodontol 2000 1999;19:7-172.

2. Lynch S, Genco R, Marx R, eds. Tissue Engineering: Applications in Maxillofacial Surgery and Periodontics. Carol Stream, IL.: Quintessence Publishing Company; 1999:

3. Thesleff I, Nieminen P. Tooth morphogenesis and cell differentiation. Curr Opin Cell Biol 1996;8:844-850.

4. Maas R, Bei M. The genetic control of early tooth development. Crit Reu Oral Biol Med 1997;8:4-39.

5. MacNeil RL, Thomas HF. Development of the murine periodontium. I. Role of basement membrane in formation of a mineralized tissue on the developing root dentin surface. J Periodontol 1993;64:95-102.

6. Fong CD, Slaby I, Hammarström L. Amelin: an enamelrelated protein, transcribed in the cells of epithelial root sheath. J Bone Miner Res 1996;11:892-898.

7. Hu CC, Fukae M, Uchida T, et al. Sheathlin: cloning, 
cDNA/polypeptide sequences, and immunolocalization of porcine enamel sheath proteins. J Dent Res 1997;76: 648-657.

8. Krebsbach PH, Lee SK, Matsuki Y, Kozak CA, Yamada KM, Yamada Y. Full-length sequence, localization, and chromosomal mapping of ameloblastin - a novel toothspecific gene. J Biol Chem 1996;271:4431-4435.

9. Luo W, Slavkin HC, Snead ML. Cells from Hertwig's epithelial root sheath do not transcribe amelogenin. $J$ Periodont Res 1991;26:42-47.

10. Slavkin HC, Bessem C, Fincham AG, et al. Human and mouse cementum proteins immunologically related to enamel proteins. Biochim Biophys Acta 1989;991:12-18.

11. Bosshardt DD, Nanci A. Immunodetection of enameland cementum-related (bone) proteins at the enamelfree area and cervical portion of the tooth in rat molars. J Bone Miner Res 1997;12: 367-379.

12. Bosshardt DD, Selvig KA. Dental cementum: the dynamic tissue covering of the root. Periodontol 2000 1997;13:41-75.

13. Lindhe J. ed. Emdogain. A biological approach to periodontal regeneration. J Clin Periodontol 1997;24:657714.

14. Hammarström L, Heijl L, Gestrelius S. Periodontal regeneration in a buccal deshiscence model in monkeys after application of enamel matrix proteins. J Clin Periodontol 1997;24:669-677.

15. Gestrelius S, Andersson C, Johansson AC, et al. Formulation of enamel matrix derivative for surface coating. Kinetics and cell colonization. J Clin Periodontol 1997;24:678-684.

16. Sculean A, Reich E, Chiantella GC, Brecx M. Treatment of intrabony periodontal defects with an enamel matrix protein derivative (Emdogain): a report of 32 cases. Int J Periodontics Restorative Dent 1999;19:157-163.

17. Heijl L, Heden G, Svardstrom G, Ostgren A. Enamel matrix derivative (Emdogain) in the treatment of intrabony periodontal defects. J Clin Periodontol 1997;24: 705-714.

18. Gestrelius S, Andersson C, Lidstrom D, Hammarstrom $\mathrm{L}$, Somerman $\mathrm{M}$. In vitro studies on periodontal ligament cells and enamel matrix derivative. $J$ Clin Periodontol 1997;24:685-692.

19. D'Errico JA, Berry JE, Ouyang H, Strayhorn CL, Windle JJ, Somerman MJ. Employing a transgenic animal model to obtain cementoblasts, in vitro. J Periodontol 2000;71:63-72.

20. Chen D, Chen H, Feng JQ, et al. Osteoblastic cell lines derived from a transgenic mouse containing the osteocalcin promoter driving SV40 T-antigen. Mol Cell Differentiation 1995;3:193-212.

21. D'Errico JA, MacNeil RL, Takata T, Berry J, Strayhorn C, Somerman MJ. Expression of bone associated markers by tooth root lining cells, in situ and in vitro. Bone 1997;20:117-126.

22. D'Errico JA, Ouyang H, Berry JE, et al. Immortalized cementoblasts and periodontal ligament cells in culture. Bone 1999;25:39-47.

23. Sudo H, Kodama HA, Amagai Y, Yamamoto S, Kasai S. In vitro differentiation and calcification in a new clonal osteogenic cell line derived from newborn mouse calvaria. J Cell Biol 1983;96:191-198.

24. Quarles LD, Yohay DA, Lever LW, Caton R, Wenstrup RJ. Distinct proliferative and differentiated stages of murine MC3T3-E1 cells in culture: an in vitro model of osteoblast development. J Bone Miner Res 1992;7:683692.
25. Franceschi RT, Iyer BS, Chi Y. Effects of ascorbic acid on collagen matrix formation and osteoblast differentiation in murine MC3T3-E1 cells. J Bone Miner Res 1994;9:843-854.

26. Xie WQ, Rothblum LI. Rapid, small-scale RNA isolation from tissue culture cells. Biotechniques 1991;11:324, 326-327.

27. Young MF, Ibaraki K, Kerr JM, Lyu MS, Kozak CA. Murine bone sialoprotein (BSP): cDNA cloning, mRNA expression, and genetic mapping. Mamm Genome 1994;5:108-111.

28. Young MF KJ, Termine JD, et al. cDNA cloning, mRNA distribution and heterogeneity, chromosomal location, and RFLP analysis of human osteopontin (OPN). Genomics 1990;7:491-502.

29. Celeste AJ, Rosen V, Buecker JL, Kriz R, Wang EA, Wozney JM. Isolation of the human gene for bone gla protein utilizing mouse and rat cDNA clones. EMBO $J$ 1986;5:1885-1890.

30. Tenenbaum HC. Role of organic phosphate in mineralization of bone in vitro. J Dent Res 1981;60(Spec. No. C):1586-1589.

31. Krebsbach PH, Kuznetsov SA, Satomurak K, Emmons RVB, Rowe DW, Robey PG. Bone formation in vivo: comparison of osteogenesis by transplanted mouse and human marrow stromal fibroblasts. Transplantation 1997;63:1059-1069.

32. Wang D, Christensen K, Chawla K, Xiao G, Krebsbach $\mathrm{PH}$, Franceschi RT. Isolation and characterization of MC3T3-E1 preosteoblast subclones with distinct in vitro and in vivo differentiation/mineralization potential. $J$ Bone Miner Res 1999;14:893-903.

33. Grzesik WJ, Kuzentsov SA, Uzawa K, Mankani M, Robey PG, Yamauchi M. Normal human cementum-derived cells: isolation, clonal expansion, and in vitro and in vivo characterization. J Bone Miner Res 1998;13:1547-1554.

34. Ingber D. In search of cellular control: signal transduction in context. J Cell Biochem Suppl 1998;31:232-237.

35. Force T, Bonventre JV. Growth factors and mitogenactivated protein kinases. Hypertension 1998;31:152161.

36. Strayhorn CL, Garrett JS, Dunn RL, Benedict JJ, Somerman MJ. Growth factors regulate expression of osteoblast-associated genes. J Periodontol 1999;70: 1345-1354.

37. Centrella M, McCarthy TL, Kusmik WF, Canalis E. Relative binding and biochemical effects of heterodimeric and homodimeric isoforms of platelet-derived growth factor in osteoblast- enriched cultures from fetal rat bone. $J$ Cell Physiol 1991;147:420-426.

38. Tanaka H, Liang CT. Effect of platelet-derived growth factor on DNA synthesis and gene expression in bone marrow stromal cells derived from adult and old rats. $J$ Cell Physiol 1995;164:367-375.

39. Hsieh SC, Graves DT. Pulse application of plateletderived growth factor enhances formation of a mineralizing matrix while continuous application is inhibitory. $J$ Cell Biochem 1998;69:169-180.

40. Butler WT, Ridall AL, McKee MD. Osteopontin. In: Bilezikian JP, Raisz LG, Rodan GA, eds. Principles of Bone Biology. San Diego: Academic Press; 1996:167182.

41. Hunter GK, Hauschka PV, Poole AR, Rosenberg LC, Goldberg HA. Nucleation and inhibition of hydroxyapatite formation by mineralized tissue proteins. Biochem $J$ 1996;317:59-64.

42. Ducy P, Zhang R, Geoffroy V, Ridall AL, Karsenty G. 
Osf2/Cbfa1: a transcriptional activator of osteoblast differentiation. Cell 1997;89:747-754.

43. Bronckers AL, Price PA, Schrijvers A, Bervoets TJ, Karsenty G. Studies of osteocalcin function in dentin formation in rodent teeth. Eur J Oral Sci 1998;106:795807.

44. Boskey AL, Maresca M, Ullrich W, Doty SB, Butler WT, Prince CW. Osteopontin-hydroxyapatite interactions in vitro: inhibition of hydroxyapatite formation and growth in a gelatin-gel. Bone Miner 1993;22:147-159.

45. Hunter GK, Kyle CL, Goldberg HA. Modulation of crystal formation by bone phosphoproteins: structural specificity of the osteopontin-mediated inhibition of hydroxyapatite formation. Biochem J 1994;300:723-728.

46. Hunter GK, Goldberg HA. Nucleation of hydroxyapatite by bone sialoprotein. Proc Natl Acad Sci (USA) 1993;90: 8562-8565.

47. Fincham AG, Moradian-Oldak J, Diekwisch TG, et al. Evidence for amelogenin "nanospheres" as functional components of secretory-stage enamel matrix. J Struct Biol 1995;115:50-59.

48. Takagi Y, Fujita H, Katano H, Shimokawa H, Kuroda T. Immunochemical and biochemical characteristics of enamel proteins in hypocalcified amelogenesis imperfecta. Oral Surg Oral Med Oral Pathol Oral Radiol Endod 1998;85:424-430.

49. Lyngstadaas SP, Risnes S, Sproat BS, Thrane PS, Prydz HP. A synthetic, chemically modified ribozyme eliminates amelogenin, the major translation product in developing mouse enamel in vivo. EMBO $J$ 1995;14:52245229.

50. Doi Y, Eanes ED, Shimokawa H, Termine JD. Inhibition of seeded growth of enamel apatite crystals by amelogenin and enamelin proteins in vitro. J Dent Res 1984; 63:98-105.

51. Aoba T, Fukae M, Tanabe T, Shimizu M, Moreno EC. Selective adsorption of porcine-amelogenins onto hydroxyapatite and their inhibitory activity on hydroxyapatite growth in supersaturated solutions. Calcif Tissue Int 1987;41:281-289.
52. Hunter GK, Curtis HA, Grynpas MD, Simmer JP, Fincham AG. Effects of recombinant amelogenin on hydroxyapatite formation in vitro. Calcif Tissue Int 1999; 65:226-231.

53. Simmer JP, Lau EC, Hu CC, et al. Isolation and characterization of a mouse amelogenin expressed in Escherichia coli. Calcif Tissue Int 1994;54:312-319.

54. Robinson C, Brookes SJ, Shore RC, Kirkham J. The developing enamel matrix: nature and function. Eur $J$ Oral Sci 1998;106(Suppl. 1):282-291.

Send reprint requests to: Dr. Martha Somerman, Department of Periodontics/Prevention/Geriatrics, University of Michigan, School of Dentistry, 1011 North University Avenue, Ann Arbor, MI 48109-1078. Fax: 734/763-5503; e-mail: somerman@umich.edu

Accepted for publication June 5, 2000. 